\title{
DISCURSO DE AGRADECIMENTO DO PROFESSOR LUIS EDUARDO SCHOUERI POR OCASIÃO DA POSSE PELA TITULARIDADE EM LEGISLAÇÃO TRIBLTÁRIA
}

\author{
Luis Eduardo Schoueri \\ Professor Titular de Direito Econômico e \\ Financeiro pela Faculdade de Direito da \\ Universidade de São Paulo.
}

Exmo. Sr. Prof. Dr. Eduardo Cesar Silveira Vita Marchi, mui digno Diretor da Faculdade de Dircito da Universidade de São Paulo;

Exmo. Sr. Prof. Dr. Fábio Nusdeo, que, ım nome da Congregação. hoje me recebe;

Exmos. Srs. Professores da Faculdade de Direito da Universidade de São Paulo e demais membros da Congregação;

Queridos alunos, razão de ser desta solenidade;

Meus amigos e colegas que, num gesto de carinho para com a minha pessoa e a do ilustre Professor Titular Calixto Salomão Filho, honram-nos com sua presença;

Meus Pais, Robert e Maria Lúcia e, na pessoa desta última, tenho a emoção de reverenciar. neste salão sagrado, a memória de seu avô (portanto, meu bisavô), o Ministro Costa Manso, que aqui se bacharelou e anos depois recebeu o título de doutor honoris causa;

Denise, minha namorada desde os tempos do Colégio; Ana Carolina e Luis Roberto, frutos do amor que nos une e certeza de que vale a pena viver;

Senhoras e Senhores!

Este ambiente, este rito, esta assistência, tudo o que vivi compõem em minha mente a miragem de outra solenidade, que se dava no grande momento em que se investia um cavaleiro.

Escolhido o novo paladino, cra conduzido ao supedâneo da igreja pelo rei, ou o nobre que o haveria de armar. Ali, ele encontrava. sobre uma almofada, suas futuras armas; outra almofada, colocada diante da primeira, era apontada pelo suserano. O futuro cavaleiro deveria ser deixado a sós, de joelhos, por toda a noite, para contemplar suas armas e refletir sobre as razões que o levaram àquela honraria e sobre a missão que o esperava. 
Também a investidura no cargo de Professor Titular da Faculdade de Direito da Universidade de São Paulo exige idêntica reflexão: contemplo as armas que passo a ostentar com orgulho - a Cátedra de Direito - para ver desfilarem por minha mente todos aqueles que me trouxeram até aqui.

É. assim que vem à mente minha familia. Meus pais è irmãos, num primeiro momento, minha esposa e filhos, até hoje. Jamais deixaram de acreditar que este momento chegaria. Num sacrifício que só o verdadeiro amor permite, abriram mão de noites, fins de semana, férias inteiras. por conta de meus estudos. Eis porque é a eles que dedico esta conquista.

Contemplando este doutoral, outros rostos vão surgindo, alguns aqui presentes, outros, apenas na memória e na saudade.

Este momento de reflexão me traz o nome do Prof. Fábio Nusdeo, cujas palavras de saudação muito me emocionaram. Regozijo-me com a feliz decisão dessa Congregação, por intermédio de seu Diretor, na escolha daquele que deveria receber seus mais novos integrantes.

$\mathrm{Na}$ pessoa do Prof. Nusdeo, meu pensamento se dirige aos bancos escolares do Colégio São Luis. onde ambos estudamos. A rigidez dos jesuítas marca. de um lado, a formação moral e religiosa de seus alunos; de outro, traz-lhes a purseverança e a predisposição ao trabalho, na compreensão de que os dons de Deus implicam responsabilidade para quem us recebe.

Foi o Prol: Nusdeo, para mim. um modelo nestas Arcadas. De início. professor admirável; mais tarde, o conselheiro a quem eu primeiro procurei, indagandolhe se seria prematuro, de minha parte, concorrer à vaga de Professor Titular do Departamento de Direito Econômico e Financeiro destas Arcadas.

('om a aposentadoria do Prof. Nusdeo, houve por bem o Conselho Departamental confiar ao ilustre Professor Titular Hermes Marcelo Huck a condução dos trabalhos na áréa do Direito Econômico -.. imediatamente convertendo-se no novel Direito Econômico Internacional - ficando vaga, assim, a área de Legislação Tributária, até então conduzida por aquele Titular.

É assim que, em situação inusual, vejo-me simultaneamente sucessor de dois queridos amigos e mestres. Do Prof. Nusdeo, em virtude de eu ocupar, formalmente, a vaga deixada por $\mathrm{S}$. Exa.

Ratione Materiae, entretanto, sucedo, imediatamente, o Prof. Herınes Marcelo Huck. Também a figura deste Professor Titular surge nesta reflexão. Foi quem primeiramente me acolheu no Departamento de Direito Econômico Financeiro. quando 
eu, recém aprovado no concurso de livre-docência desta Academia, aqui quis ensinar. Convidou-me o Prof. Huck a assisti-lo em disciplinas sob sua responsabilidade na pósgraduação desta Faculdade. Os debates que travamos naquelas aulas, abriram-me o caminho para investigações sobre o entrelaçamento do Direito Tributário com o Direito Econômico.

Ao lembrar o Prof. Huck, também surgem os nomes dos demais ocupantes da Cátedra de Legislação Tributária: Prof. José Afonso da Silva e *a aqui devo mencionar com indisfarçável orgulho -. Rubens Gomes de Sousa, autor do anteprojeto do nosso Código Tributário Nacional.

A Cátedra de Legislação Tributária compartilha os estudos tributários com sua co-irmã, Direito Tributário, hoje nas mãos seguras do Professor Titular Paulo de Barros Carvalho, cuja Tese, Fundamentos Jurídicos da Incidência Tributária, defendida nesta Casa, tornou-se obra de referência em diversos países, com várias traduções.

Ao me referir à Cátedra de Direito Tributário, emerge a figura de seu fundador, o Prof. Ruy Barbosa Nogueira, por cujas mãos ingressei nos estudos de Direito Tributário. Entusiasta desta matéria, o Prof. Ruy não media sacrifícios para que todos descobrissem o gosto de estudá-la. Germanista, foi o Prof. Ruy Barbosa Nogueira quem me incentivou a completar minha pesquisa de pós-graduação na Alemanha, recomendando-me ao Prof. Klaus Vogel, cujas aulas formaram os alicerces de meus estudos de Direito Tributário Internacional.

Deixando o Prof. Ruy Barbosa Nogueira sua cátedra, foi ela ocupada por Alcides Jorge Costa. Culto e provocativo. o Prof. Alcides Jorge Costa ensinou-me a jamais ficar satisfeito com certezas: a alegria do cientista está na descoberta de dúvidas, já que são elas que provocam novas pesquisas. Incentivou-me a trilhar a livre-docência e soube dizer quando eu estava amadurecido para disputar a titularidade. Mais do que scu discípulo, intitulo-me seu amigo.

F́ a amizade que me traz à mente outros mestres. Para não correr o risco de ferir a modéstia de tantos, deixo de citá-los. Minha consciência não me deixaria em paz, entretanto, se não dirigisse palavra de agradecimento ao Catedrático que me abriu as portas ao Direito e à pesquisa. Refiro-me ao Prof. Tércio Sampaio Furraz Júnior. Desde suas aulas de Introdução ao Estudo do Direito, o Prof. Tércio inspirava o raciocinio investigativo. Juntamente com o Prof. José Eduardo Faria, coordenava o Prof. Tércio um projeto de pesquisa, o Pet-Capes, por meio do qual uns poucos alunos 
de graduação recebiam bolsa de estudos para aprofundarem seus estudos, tendo o privilégio de participar de seminários semanais com aqueles professores. Acreditavam seus coordenadores que sua iniciativa fomentaria o gosto pela pesquisa e - quem sabe novos quadros docentes. Ao ingressar no programa, firmei com os coordenadores o compromisso com a atividade docente. Daí a minha alegria de, agradecendo a oportunidade recebida, poder dizer-lhes que a promessa foi cumprida.

Ressurge em meu pensamento a figura daquele cavaleiro, que reflete diante de suas novas armas: não the cabe apenas ponderar sobre o que o trouxe até aquele momento; também deve firmar seus propósitos com relação ao que o espera.

No presente caso, a reflexão tem o peso de um propósito a ser mantido por mais de três décadas na titularidade.

Revelo a minha missão: encorajado pela memória do Catedrático e pela amizade de meus colegas, vejo-me investido na tarefa de promover estudos na seara tributária, no tripé ensino, pesquisa, extensão.

Oferecerei campo adequado para os debates teóricos, com a abertura que o ambiente universitário exige. Oxalá possa eu contribuir para ver florescer, nesta casa, a boa semente plantada por Ruy Barbosa Nogueira. Não me curvarei a modelos fechados. Abrir-me-ei para as diversas escolas, fugindo de idéias preconcebidas.

Promoverei o intercâmbio com os grandes centros de pensamento, caminhando na mesma marcha que a Universidade de São Paulo se propõe. O movimento de internacionalização não se limitará à busca do conhecimento do Direito Comparado. Esta será, sem dúvida, tônica dos estudos; não me contentarei, entretanto, com tal posição passiva. Ao contrário, estando em sintonia com os debates acadêmicos que se travam alhures. caberá a São Paulo reivindicar - por sua tradição. mas principalmente pela sericdade de seus trabalhos - um lugar ativo, fazendo repercutir sua voz em outros fôros. Legitimará tal pretensão, de um lado, a pesquisa, mas de outro, a difusão das idéias que haverão de frutificar no Largo de São Francisco.

Acredito nesta Universidade. Não é por outra razão que se encontra em fase de conclusão, no Instituto Brasileiro de Direito Tributário, a biblioteca para estudos de Direito Tributário Internacional c Comparado, com acervo inicial legado por Ruy Barbosa Nogueira. Com aquela biblioteca e com as pesquisas que se desenvolverão no Departamento de Direito Econômico e Financeiro. já posso vislumbrar as Arcadas abrindo seus braços a estudantes de outros tistados brasileiros e de países vizinhos. Trabalharei para que a Faculdade de Direito da Universidade de São Paulo. contando com o firme apoio do Instituto Brasilciro de Direito Tributário, se 
torne, em curto espaço de tempo, pólo de referência nos estudos tributários. Com a colaboração de estudantes de outras regiões, a pesquisa não se limitará a temas locais, passando a enfocar a Legislação Tributária dentro da realidade em que se insere.

Dentre os desafios da Legislação Tributária, merece destaque a interdependência econômica internacional, marcada por uma rede de tratados. que provocam reflexos tributários. O crescimento gigantesco das trocas comerciais já não permite que o estudioso da Legislação Tributária ignore os reflexos de uma mesma transação em diversos países.

O estudo da Legislação Tributária, por outro lado, haverá de ultrapassar a mera relação fisco/contribuinte, para alcançar a dimensão fisco/fisco, quando se investigam critérios jurídicos adequados para a distribuição da carga tributária entre os Estados envolvidos em uma relação internacional.

A dimensão econômica internacional da tributação revela-se em temas como a contenção da prática da concorrência tributária predatória, inclusive por meio de paraisos fiscais; a adequada fixação de preços de transferência entre partes relacionadas; o emprego dos acordos de bitributação; a harmonização tributária nos blocos econômicos e a tributação do comércio eletrônico.

Também no cenário doméstico, a pesquisa da Legislação Tributária dará ênfase à interdisciplinariedade. O fenômeno da tributação será estudado sob o prisma de sua funcionalidade, quando o efeito do tributo sobre a ordem econômica não mais poderá ser ignorado; o teste de constitucionalidade da norma tributária não se limitará a questões formais; a elas se agregarão questões decorrentes da inserção daquelas normas na Ordem Econômica da Constituição.

O estudo dos novos desafioos da Legislação Tributária não haverá de deixar para trás o conhecimento consolidado na Escola de São Paulo. É tradição desta Escola estudar o fenômeno tributário sob perspectiva histórica, com suas três dimensões: normativa, fática e axiológica.

Finalmente, caberá ao estudioso de Legislação Tributária compreendê-la no tempo em que ela se insere. Afinal, somente em tempos bastante recentes foram positivadas, de modo exaustivo, no texto constitucional, as limitações ao exercício do poder de tributar que se desenvolveram num periodo histórico marcado pela contenção do poder do Soberano pelos representantes do povo. Paradoxalmente. é também nos tempos atuais que assistimos a sua flexibilização em níveis jamais imaginados. 
Ao mesmo tempo em que se deve reconhecer a necessidade de o Direito adaptar-se às novas exigências sociais, não poderá o jurista calar-se quando vir ameaçada a própria ordem juridica. Refiro-me. aqui, por exemplo, à "suave perda da liberdade" que se assiste quando, ao arrepio do princípio da legalidade, beneficios fiscais vêm sendo concedidos sem o devido exame por parte do Poder Legislativo, tornando-se os beneficiários caudatários dos favores do Poder Executivo, com o justo temor de verem seu slatus tributário alterado a qualquer momento, já que inexiste qualquer garantia de seu exercício.

Sr. Diretor.

Srs. Professores,

Caros alunos,

Sras. e Srs.

Não posso deixar de manifestar a emoção que sinto ao pronunciar essas palavras, em nosso Salão Nobre. Ingressando nesta Faculdade, os alunos logo se encantam pelo novo ambiente. A palavra "tradição" assume um sentido concreto, que aqui se exterioriza em cada canto. Muito especialmente, neste ambiente, onde encontramos os bustos das mais ilustres figuras da história c das artes, que passaram pelos bancos da "Velha e Sempre Nova Academia.

Logo ao lado, temos a Sala das Becas e a Sala da Congregação. Como deixar de reviver o sonho deste estudante. ao encontrar. naqueles ambientes, expressos em placas douradas, nomes dos mais admirados pensadores do Direito? Não ousava acreditar que, algum dia, viesse ombrear-me com os doutos. Quem dera - pensava quando estudante - pudesse um dia sentar-me ao lado dos Professores da Academia do Largo de São Francisco!

O delírio transformou-sc em objetivo e para tanto, resolvi enfrentar todas as etapas necessárias a sua concretização. Despertava em mim uma nova vocação: o magistério. A cada aula proferida, uma alegria. Mas o sonho de lecionar não se realicaria. enquanto não o fosse nestas Arcadas. Por anos, como docente voluntário, ministrei aulas na graduação e na pós-graduação. A felicidade não era completa em virtude do estado precário da minha atividade: sabia que, por não integrar o quadro dos docentes desta Faculdade, poderia eu, a qualquer momento, vir a ser afastado do convívio com os alunos das Arcadas. 
Daí a alegria deste momento: contrariando o poeta, devo dizer que aquela tristeza teve fim, e hoje, minha felicidade soa imorredoura: darei aulas, na Faculdade de Direito da Universidade de São Paulo, como seu Professor Titular, enquanto minha saúde assim o permitir. Quando, mais tarde, limitações de ordem legal me vierem forçar a deixar a atividade acadêmica, ainda assim, a felicidade não haverá de encerrar, já que, Deus o permita, haverei de ter a satisfação do dever cumprido.

No discurso de sua posse, o Prof. Fábio Nusdeo, com a erudição que o singulariza, lcmbrava que a cerimônia, muito mais que coroação, trata-se de investidura. E investidura implica missão. É esse o alerta do Mestre que ora ressoa em minha mente, lembrando-me aqueles que me confiaram a mais sagrada das missões: a de formar novas gerações. E, no caso presente, novas gerações das Arcadas, por mais de três décadas.

Mas permita-me, Prof. Nusdeo, mais uma vez recordar nossa formação com os jesuítas, para traçar o paralelo entre a investidura c a ordem, no âmbito daquela congregação religiosa, quando se exige, do recém admitido, a pronúncia de alguns votos. $\dot{E}$ assim que me vejo, nesse momento, instado a pronunciar, também eu, meus votos definitivos.

Faço, neste momento, o voto de ensinar o Direito, porque é nele que acrudito, e somente pode bem ensinar aquele que crê no que ensina.

Faço, neste momento, o voto de ensinar o Direito. por acreditar que é da formação do jurista que depende a transformação da Justiça e esta é a aspiração maior da Sociedade.

Faço, nesse momento, o voto de ensinar o Direito, para suscitar nos alunos o espírito crítico, requisito para a evolução do conhecimento.

Faço, neste momento, o voto de ensinar o Direito, porque é o título de Professor destas Arcadas aquele que desejo carregar com orgulho, e este sentimento apenas faz sentido se, seguindo os passos de meus Mestres, souber que Professor não é aquele que ostenta um título, mas aquele que se sente em casa na sala de aula.

Faço, neste momento. o voto de ensinar o Direito, porque sei que ensinar é um dom de Deus e se Dele o recebi, é para exercê-lo com retidão centusiasmo.

Faço, neste momento. o voto de ensinar o Direito, para que mcus filhos, aqui presentes, saibam que seu pai. nestas Arcadas, estudou e ensinou; ensinando, aprendeu: $e$ aprendeu que devia ensinar. para jamais deixar de aprender.

Muito obrigado. 


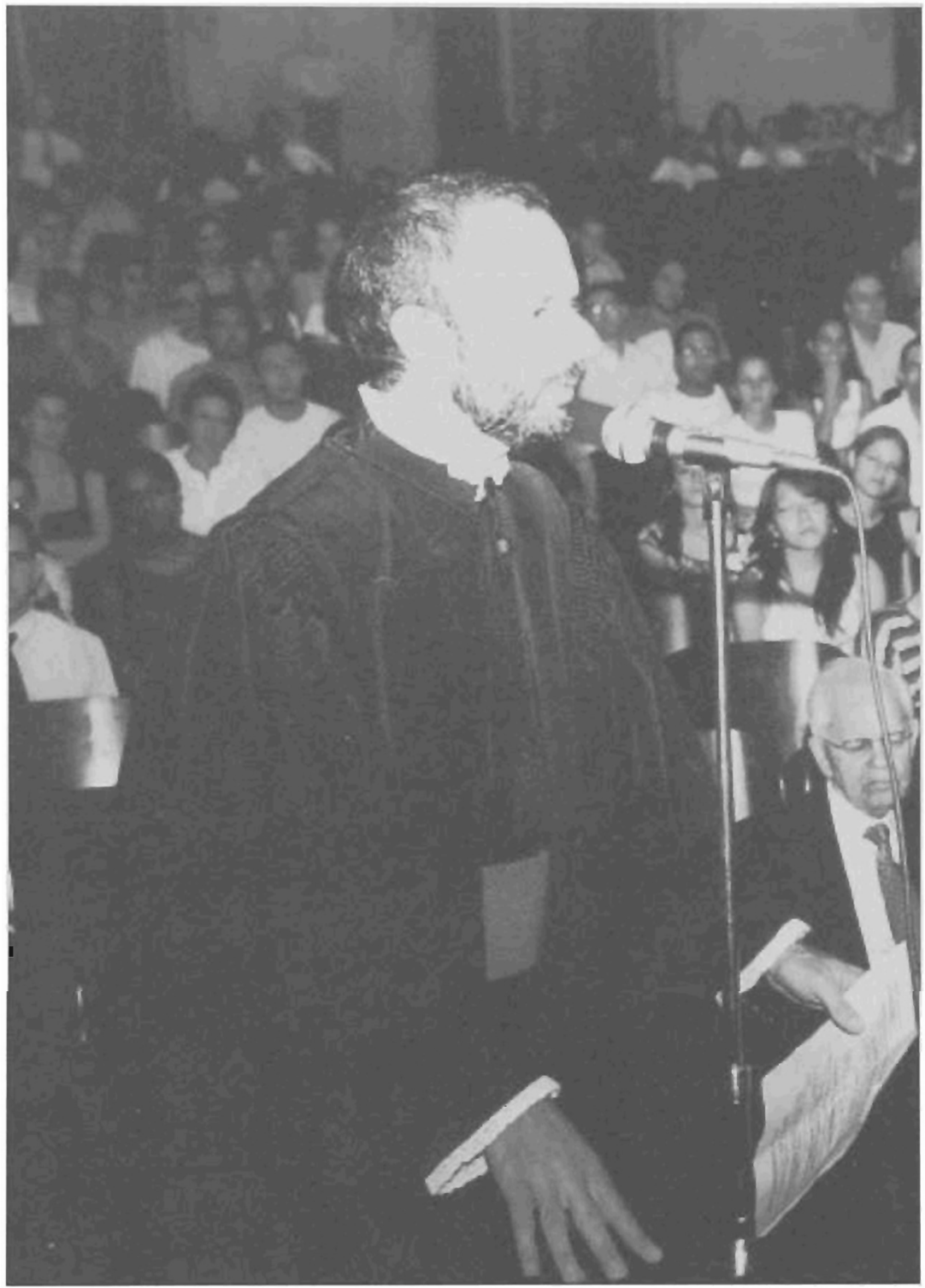

Professor Luis Eduardo Schoueri 